\title{
Impact of climate change on evaluation of future water demand in the Euphrates and Aleppo basin, Syria
}

\author{
ALAA ALDEN ALAZZY, HAISHEN LÜ \& YONGHUA ZHU \\ State Key Laboratory of Hydrology-Water Resources and Hydraulic Engineering, College of Hydrology and Water \\ Resources, Hohai University, Nanjing 210098, China \\ azzy22@hotmail.com
}

\begin{abstract}
Syria is one of the Middle Eastern countries that suffer from scarcity in water resources availability, which affects the growth and development of economic activities. In this research, the Water Evaluation and Planning (WEAP) model is applied to evaluate future water demand in the Euphrates and Aleppo basin (EAB), Syria, by taking into account the climate change that may affect water demand in the domestic, industrial, and agricultural sectors until 2050. The climate change projections of temperature and precipitation were assessed using a new version of the MAGICC/SCENGEN tool with two greenhouse gas emissions scenarios (A2 and B2) of the Intergovernmental Panel on Climate Change (IPCC). Based on the results of IPCC (A2, B2) scenarios projections, the EAB basin is likely to face a decrease in precipitation amount by $21 \%$ according to $\mathrm{A} 2$ and by $12 \%$ according to $\mathrm{B} 2$, while temperature would increase by about $2.5^{\circ} \mathrm{C}$ according to $\mathrm{A} 2$ and by $2^{\circ} \mathrm{C}$ according to $\mathrm{B} 2$. Within the three scenarios adopted in this research: (1) available technology development; (2) increasing treated wastewater in agriculture and industry sectors; (3) and two combined scenarios, the results of the simulation demonstrated that the proposed scenarios are effective for reducing stressors on EAB's water resources, but are not sustainable to bridge the gap between demand-supply by the year 2050, which leads to the deterioration of the available water resources.
\end{abstract}

Key words MAGICC/SCENGEN tool; water resources management; water demand; climate change; WEAP; Euphrates and Aleppo basin

\section{INTRODUCTION}

Changes in temperature and precipitation patterns are likely to affect the hydrologic processes and water resources available for agriculture, population, mining, industry, aquatic life and hydropower. Climate changes will accelerate the global hydrologic cycle with an increase in the surface temperature, changes in precipitation patterns and evapotranspiration rates (Bates et al. 2008).

The phenomenon of climate change is considered today to be one of the most important discussed issues and contemporary challenges; it has aroused much debate and interest at both national and global levels. Syria cannot be separated from what is happening in the rest of the world. Despite the fact that Syria is not considered a prime contributor to the global emissions of gases (greenhouse), it may be affected by the possible consequences of world climate change (Meslmani 2010).

The 4th Assessment Report of the Intergovernmental Panel on Climate Change (IPCC 2007a) projects strong changes in climate across Syria. Temperatures are expected to increase, while at the same time substantial decreases in precipitation are projected. These elevated temperatures will result in higher evapotranspiration demands and this, in combination with decreases in precipitation, will severely stress the water resources in the region.

As a result of the above discussion, climate change would likely limit the water supply requirements on a relatively short term, which leads to an intensification of water deficits in various critical basins of Syria and reducing the contribution of dams to irrigation and the potential contribution of artificial lakes to drinking water and irrigation systems during dry seasons.

One of the most effective tools to project precipitation and temperature changes is the MAGICC/SCENGEN tool (Wigley 2008) which based on the climate change scenarios of the IPCC. It is used in many fields of study (Fordham et al. 2011, Roshan et al. 2012). The outputs from the projections of MAGICC/SCENGEN models were used in the Water Evaluation and Planning (WEAP) software, developed by the Stockholm Environment Institute's US Center (SEI, 2013) for analysis of the gap between demand and supply on water in the future.

Finally, the objective of this study is to assess water demand for the Euphrates and Aleppo basin (denoted by EAB) up to the year 2050, taking into account the effect of changes in climate mainly on water resources in this particular basin. 


\section{STUDY AREA AND DATA}

\section{Study area}

The EAB basin is located in eastern Syria, bordering Turkey to the north; Tigris and Khabour basin to the east; Iraq to the south and both Orontes and al-Badieh basins to the west, as shown in Fig. 1. The basin is distributed among three cities: Aleppo, Al-Raqqa and Deirez-zor. The area of study basin covers about $51238 \mathrm{~km}^{2}$, which represents approximately $28 \%$ of the area of Syria, with a total estimated population of 5.9 million inhabitants.

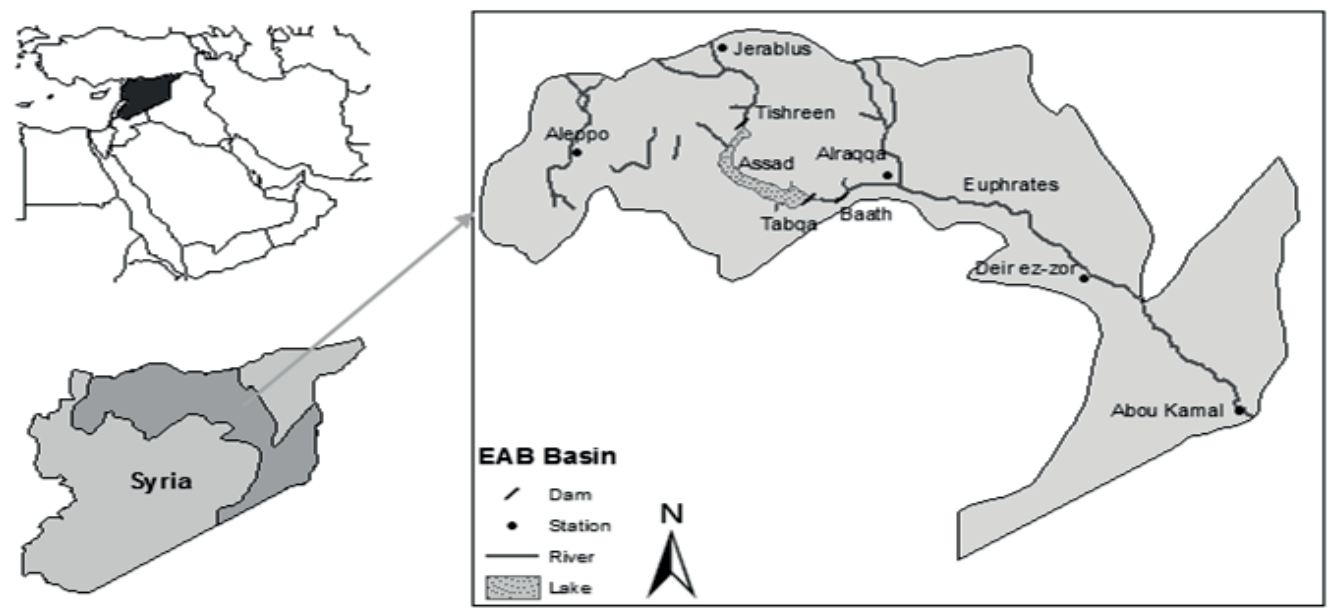

Fig. 1 Map of Syria with study area.

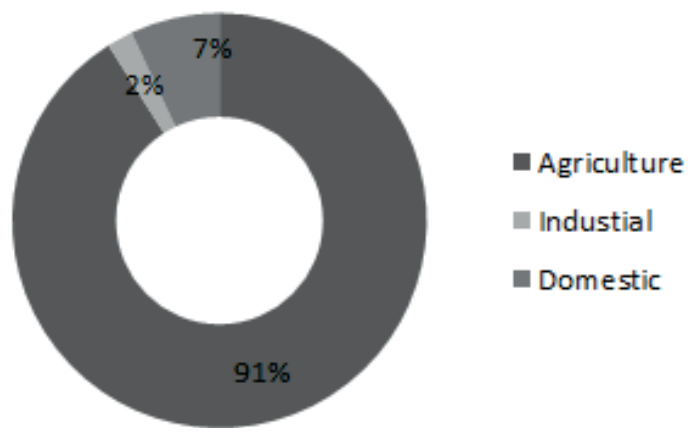

Fig. 2 The water demand requirements by sector for EAB basin (MoI 2012).

The Euphrates is the biggest river flowing in Syria, with a total length of $680 \mathrm{~km}$. It originates in Turkey, flows through Syria, and joins the Tigris in Iraq to form the Shatt al Arab, which discharges into the Persian Gulf. Three dams have been constructed on the Euphrates in Syria (Tabqa, Baath and Tishreen). The mean annual rainfall decreases from $300 \mathrm{~mm}$ in the northern regions along the border, to $150 \mathrm{~mm}$ in the middle reach of Euphrates valley and $100 \mathrm{~mm}$ at Abou Kamal. Water use in the EAB Basin focuses on irrigation, hydropower, industry and drinking water supply.

The total water demand for agricultural, domestic and industrial needs were in 2008 about 7003, 526 and $153 \mathrm{MCM}$ (millions $\mathrm{m}^{3}$ ) according to the Ministry of Housing and Construction (MoHC 2008) and the Ministry of Irrigation (MoI 2012). More than $90 \%$ of available resources are used for the irrigation, as seen in Fig. 2.

\section{Data}

The required database of this research were derived from various institutions, such as the MoHC, the MoI, in addition to the five hydrologic control stations (Jerablus, Aleppo, Deir ez-zor, Abou Kamal and AlRaqqa) which are positioned in the main stream of the EAB basin. The two climate 
change scenarios (A2 and B2) of the IPCC's fourth Special Report on Emission Scenarios (SRES) were used in this paper (IPCC 2007b). This study covers the period 1990-2010 for the base year (denoted by 2008s) and covers the two future periods: 2011-2030 and 2031-2049 for the future year (denoted by 2020s and 2040s, respectively).

\section{MATERIAL AND METHODS}

\section{MAGICC/SCENGEN Tool}

Many climate change tools have been developed and are currently in use across the world. However, there is no simple way for decision makers and planners to find out which climate compatible development tools are most appropriate to their work and local circumstances.

In this study, the Model for the Assessment of Greenhouse-Gas Induced Climate Change/Scenario Generator (MAGICC/SCENGEN) (Version 5.3) was used to obtain monthly projected changes in temperature and precipitation, based on climate change scenarios, for the $\mathrm{EAB}$ Basin. The reader can download the freely available software package from (http://www.cgd.ucar.edu/cas/wigley/magicc/). Further details of the software are provided in a companion Technical Manual (Wigley 2008).

The MAGICC/SCENGEN tool has been designed as an accessible piece of software that uses emissions scenarios for greenhouse gases, reactive gases, and sulphur dioxide in order to construct predictions of global mean temperature, sea level rise, and regional climate.

\section{Hydrological model}

The hydrologic model used in this study is the WEAP model, which was developed by the Stockholm Environment Institute (SEI). The water system in WEAP is represented in terms of supply sources which include: streamflow, groundwater and reservoir water, of water transfers which include: withdrawal and transmission, and of water demand which include: municipal and industrial demands, irrigation demands and hydropower energy demands (SEI 2013).

The model is semi-theoretical, continuous time, semi-distributed, and deterministic. As the model is semi-theoretical, it needs calibration and verification (Abrishamchi et al. 2007). The reader can find more details on this model elsewhere (http://www.weap21.org/).

\section{Calibration and validation of WEAP model}

In this study, the WEAP model was calibrated and validated to ensure the model discharge simulations fit the observations optimally. The streamflow data of years 1990-1998 and 20002010 were used for model calibration and validation, respectively, as shown in Fig. 3. The model was calibrated manually via trial and error method (Yates et al. 2005). The calibration parameters were spatially aggregated and modified. A description of these parameters is given in Table 1 .

In addition, we adopted statistical characteristics as a criterion for assessing the performance of a model for the calibration and validation period as shown in Table 2.

Table 1 Calibration parameters of WEAP model.

\begin{tabular}{lll}
\hline Parameter & Initial value & Step \\
\hline Effective precipitation & $100 \%$ & $\pm 0.5 \%$ \\
Runoff/Infiltration ratio & $50 / 50$ & $\pm 5 / 5$ \\
\hline
\end{tabular}

Table 2 The results of statistical analysis.

\begin{tabular}{lll}
\hline & Calibration period & Validation period \\
\hline The Root Mean Square Error (RSME) & 0.31 & 0.23 \\
The Correlation Coefficient $\left(\mathrm{R}^{2}\right)$ & 0.78 & 0.85 \\
\hline
\end{tabular}



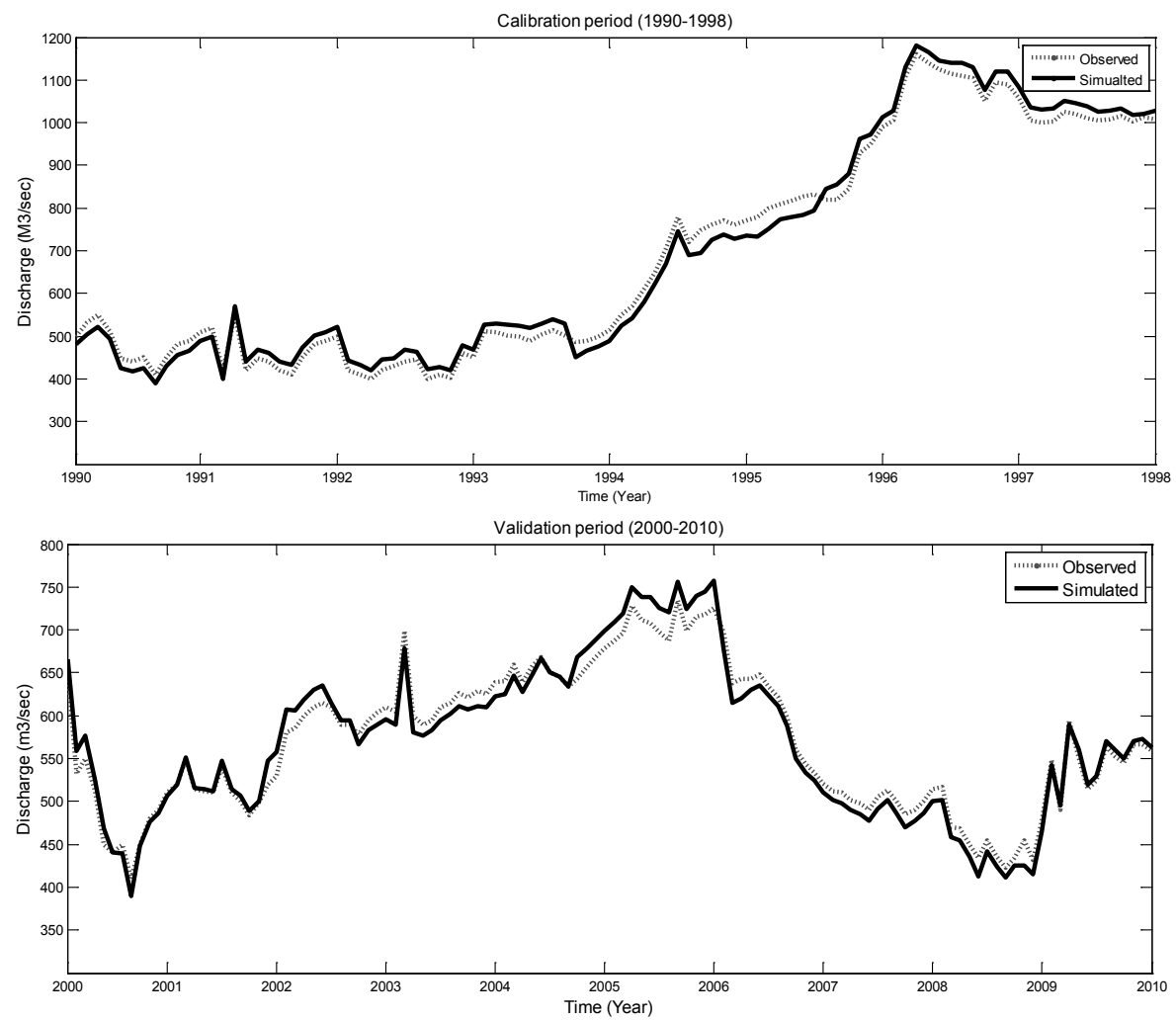

Fig. 3 Calibration and validation for the WEAP model.

It can be seen from Fig. 3 that the simulation results of validation period improved compared to calibration period as the results of the statistical analysis indicates that the WEAP model performs well in reproducing the streamflow data.

\section{Water demand scenarios}

To determine the impact of climate change scenarios (A2 and B2) on future water demand in the EAB basin until the year 2050, the study is based on the following three adaptation scenarios:

- Available technology development scenario (S1): It includes the application of best available technology such as new irrigation technologies, rainwater harvesting and using closed water cycles in industry to increase the effectiveness of the management of water resources in all economic sectors. It is assumed an increase of the water use efficiency by $35 \%$.

- Increasing treated wastewater in agriculture and industry sectors scenario (S2): As documented in INECO (2009), about 306 MCM of wastewater (treated or untreated) is reused. This scenario includes an annual increase of treated wastewater reuse in agriculture and industry of about $2 \%$, so that wastewater reused is expected to increase to $550 \mathrm{MCM}$ by 2050 .

Combining the above two scenarios S1 and S2 (S3): it includes, the implementation of assumptions S1 and S2.

\section{RESULTS AND DISCUSSION}

\section{Climate change scenarios analysis}

Figure 4 shows the future climate anomalies of mean temperature and precipitation for future years (2020s and 2040s) based on A2 and B2 scenarios at EAB basin which are calculated relative to base year (2008s). As a result of these projections, a raise in temperature is expected of the order of 1 to $2^{\circ} \mathrm{C}$ and a decrease in the amount of precipitation of the order of $10-18 \%$ during the future period (2020s and 2040s), respectively. 


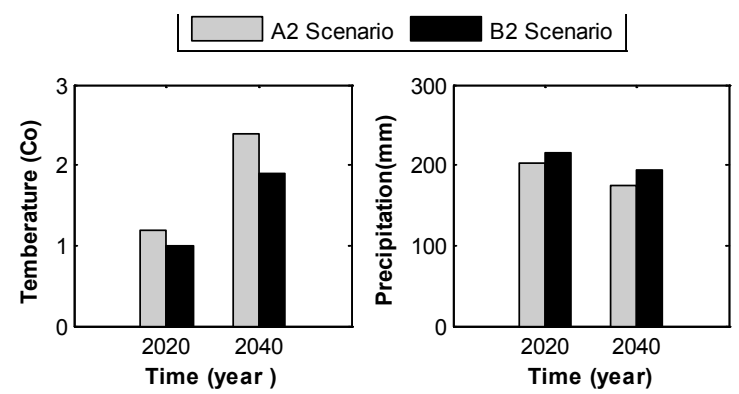

Fig. 4 The temperature anomaly and precipitation for A2and B2 scenarios.

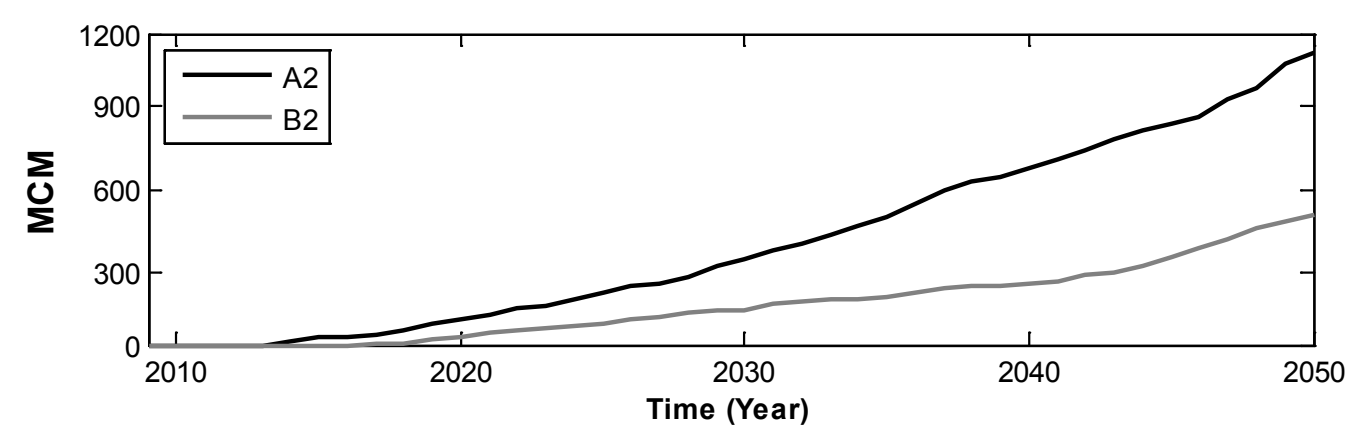

Fig. 5 Total unmet water demand based on the A2 and B2 Scenarios using WEAP model.

Impact of the scenarios (A2 and B2) on water demand: The available water resources in the study area showed sensitivity to IPCC A2 and B2 scenarios; therefore the water demand for agricultural, industrial and local needs increases as temperature rate increases and precipitation decreases.

Figure 5 illustrates the amount of unmet demand due to climate change impacts A2 and B2 without adaptation strategies. This figure shows that for both scenarios, there is significant unmet water demand over time. In A2 scenario, during the studied period, the magnitude of unmet water demand is greater in comparison with the $\mathrm{B} 2$ scenario. However, the unmet demand will increase, (1100 and $470 \mathrm{MCM}$ ) for (A2 and $\mathrm{B} 2$ ) scenarios, respectively.

The three adaptation strategies (S1, S2 and S3) were considered to mitigate the negative impacts of the climate changes on water resources availability until 2050. Figure 6 shows the total water deficit without climate change for different adaptation scenarios (the highest figure for A2 scenario and the least figure for B2 scenario). It is clear from this figure that the results of the simulation using WEAP model for adaptation scenarios have contributed to the improvement of unmet demand, compared with the analysis without adaptation strategies for B2 and A2.

The unmet demand in the $\mathrm{S} 1$ scenario has been reduced significantly in the EAB basin until 2050 by $60 \%$ and $53 \%$ for $\mathrm{A} 2$ and $\mathrm{B} 2$, respectively. This scenario will lead to increase of the volume of water available and help saving water for irrigation during the first two decades of the study period.

For the S2, there is no noticeable improvement in the coverage of water deficit. The deficiency is in water demand, of which about $870 \mathrm{MCM}$ is for A2 and $375 \mathrm{MCM}$ is for B2. However, this scenario will help to reduce the stress on freshwater to secure the requirements of water for irrigation and industry.

In comparison to the other scenarios, the $\mathrm{S} 3$ scenario represents a best case scenario, which indicates that the water supply only can accommodate up to year 2025 for the A2 scenario and up to year 2032 for the B2 scenario. Moreover it is clear that the levels of water demand coverage is largest in this scenario compared to the other scenarios where the insufficient value of water demand in 2050 is about $410 \mathrm{MCM}$ according to IPCC A2 scenario, and about $180 \mathrm{MCM}$ according to IPCC B2 scenario. 

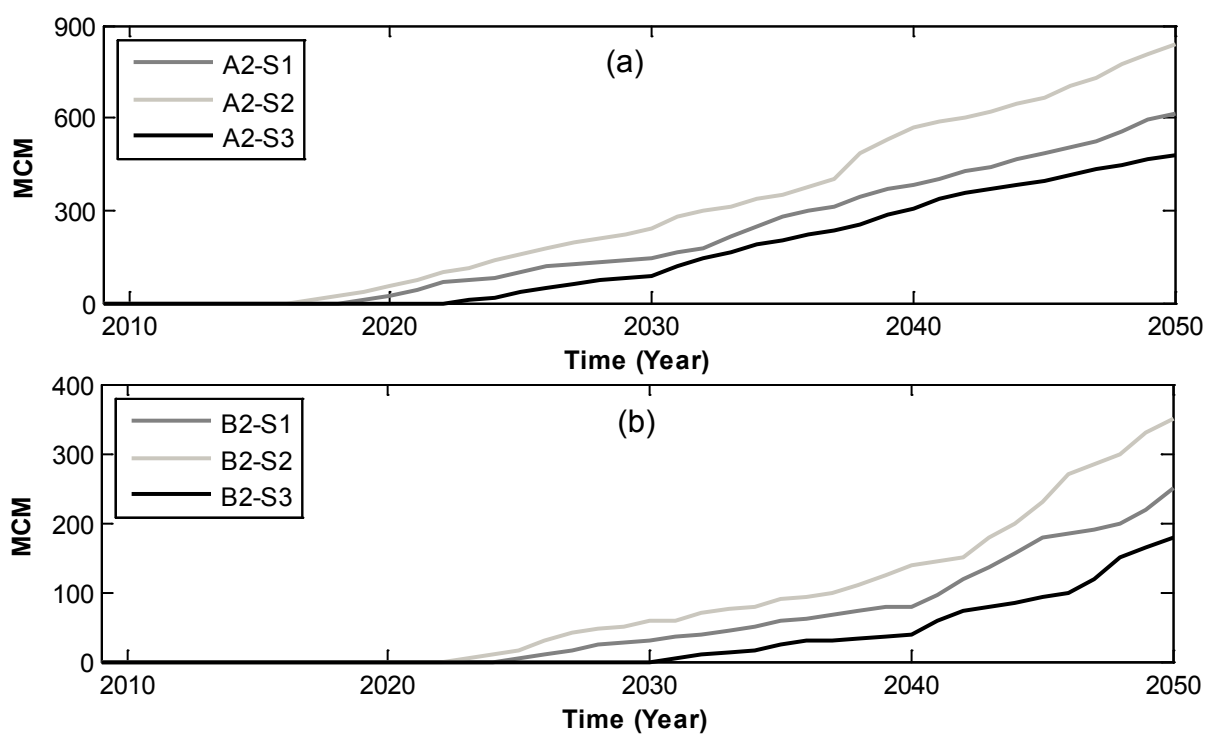

Fig. 6 Unmet demand for three adaptation strategies (S1, S2 and S3) based on the A2 and B2 scenarios using WEAP model.

\section{CONCLUSIONS}

In this research, we have used MAGICC, SCENGEN, and WEAP models to assess the future water demand under impacts of climate change with two IPCC greenhouse gases scenarios (A2 and B2) in the EAB basin. The results of simulation for all adaptation scenarios showed improvement in reducing water deficits within a relatively short-term, but the strategies proposed proved not to be enough to bridge the widening gap between supply and demand in 2050. This is reflected by the stress on the quantity and quality of available water resources in the region.

Finally, this study provides useful information for decision makers concerned with developing new water strategies and for more realistic reforms of existing policies to achieve sustainable development of water resources in the EAB basin.

\section{REFERENCES}

Abrishamchi, A. Alizadeh, A. and Tajrishy, M. (2007) Water resources management scenario analysis in the Karkheh river basin, Iran using the WEAP model. Hydrol. Sci. Technol. 23(1-4), 1-12.

Bates, B. C., et al. (2008) Climate Change and Water. Technical Paper of the Intergovernmental Panel on Climate Change; IPCC Secretariat: Geneva, Switzerland, p. 210.

Fordham, D. A., et al. (2011) Strengthening forecasts of climate change impacts with multi-model ensemble averaged projections using MAGICC/SCENGEN 5.3. Ecography 34: doi: 10.1111/j.1600-0587.2011.07398.

INECO (2009) Institutional and Economic Instruments for Sustainable Water Management in the Mediterranean Basin. (2009). Institutional framework and decision making practices for water management in Syria. Studies and Integration Consulting March; p. 68.

IPCC (2007a) Synthesis Report, Intergovernmental Panel on Climate Change, Bern, Switzerland.

IPCC (2007b) A report of Working Group I of the Intergovernmental Panel on Climate Change, Summary for Policymakers, $<$ http://www.ipcc.ch/pdf/assessment-report/ar4/wg1/ar4-wg1-spm.pdf $>$.

Meslmani, Y. (2010) Initial National Communication of the Syrian Arab Republic. United Nations Framework Convention on Climate Change. Damascus, Syria. April 2010.

MoI (2012) Ministry of Irrigation in Syria. Water resources data. http://www.irrigation.gov.sy/index.php?m=52.

MoHC (2008) Ministry of Housing and Construction in Syria. Some Arabic documents about drinking water networks in Syria.

Roshan, G. R., Moghbel, M. and Grab, S. (2012) Modeling Caspian Sea water level oscillations under different scenarios of increasing atmospheric carbon dioxide concentrations. Iranian Journal of Environmental Health Science \& Engineering 9-24: doi:10.1186/1735-2746-9-24.

SEI (2013) WEAP (Water Evaluation and Planning). Stockholm Environment Institute, Boston USA. http://sei-us.org/software/weap/.

Wigley, T. (2008) MAGICC/SCENGEN 5.3 user manual (version 2). NCAR, Boulder, CO, USA, 1-81.

Yates, D., et al. (2005) Weap21-a demand-, priority-, and preference-driven water planning model: Part 2, aiding freshwater ecosystem service evaluation. Water Int. 30(4), 501-512. 